\title{
Carbon Dioxide Insufflation in Endoscopic Submucosal Dissection: Is It an Urgent Need?
}

\author{
Chang Seok Bang and Gwang Ho Baik \\ Department of Internal Medicine, Hallym University College of Medicine, Chuncheon Sacred Heart Hospital, Chuncheon, Korea
}

See "Carbon Dioxide versus Air Insufflation in Gastric Endoscopic Submucosal Dissection: A Systematic Review and Meta-Analysis of Randomized Controlled Trials" by Ramkaji Baniya, Sunil Upadhaya, Jahangir Khan, et al., on page 464-472.

Endoscopic submucosal dissection (ESD) is a standard treatment for patients with gastrointestinal neoplasm who have a negligible risk of lymph node metastasis. ${ }^{1,2}$ ESD enables en bloc resection of gastrointestinal neoplasm and organ preservation, thus, avoiding surgical treatment.

With the advances in endoscopic skills and expertise, endoscopists have focused on ensuring the quality of recovery of patients as well as reducing procedure-related adverse events such as gastric perforation, hemorrhage, or abdominal pain.

Procedure-related gastric perforation or hemorrhage might be less significant, because it is usually managed by endoscopic hemostasis or clipping without additional surgical treatments in skilled endoscopies. However, procedure-related abdominal pain or discomfort might lower the quality of recovery of patients after gastric ESD.

Distension of the intestinal lumen is essential to ensure adequate visibility and to secure the space required for a safe procedure. ${ }^{3}$ During endoscopic procedures, a large amount of gas is insufflated (i.e., 8-18 L during diagnostic colonoscopy, which far exceeds the physiological gastrointestinal gas with a volume of $0.1-1 \mathrm{~L}) .^{4-6}$

Received: August 13, 2017 Revised: September 6, 2017

Accepted: September 15, 2017

Correspondence: Chang Seok Bang

Department of Internal Medicine, Hallym University College of Medicine, Chuncheon Sacred Heart Hospital, 77 Sakju-ro, Chuncheon 24253, Korea Tel: +82-33-240-5821, Fax: +82-33-241-8064, E-mail: csbang@hallym.ac.kr

(cc) This is an Open Access article distributed under the terms of the Creative Commons Attribution Non-Commercial License (http://creativecommons.org/ licenses/by-nc/3.0) which permits unrestricted non-commercial use, distribution, and reproduction in any medium, provided the original work is properly cited.
Room air is the most commonly used material during diagnostic and therapeutic endoscopic procedures. However, it can cause abdominal pain, because it is poorly absorbed in the intestines and is mostly excreted by belching or passage of flatus. ${ }^{3}$ Moreover, abdominal discomfort or pain due to retained gas is common. When gastric perforation occurs, the leaked air increases the intra-abdominal pressure and can induce pneumoperitoneum. Although rarely observed, air embolism is another adverse event related to ESD-induced gastric perforation. ${ }^{7-9}$ To overcome these potentially fatal adverse events, carbon dioxide $\left(\mathrm{CO}_{2}\right)$ instead of room air has been proposed as the insufflating agent, because $\mathrm{CO}_{2}$ is rapidly absorbed by tissues. $^{3}$

$\mathrm{CO}_{2}$ was proposed as the insufflating agent of the large intestine in the 1950s, and it has been used to distend the abdominal cavity for endoscopic exploration of the peritoneal cavity during laparoscopic surgery. ${ }^{10} \mathrm{CO}_{2}$ is 160 times more rapidly absorbed than nitrogen is and 13 times more rapidly absorbed than oxygen is. ${ }^{3,6,11}$ It is passively absorbed through the gastrointestinal mucosa into the bloodstream and is eventually exhaled through the lungs. ${ }^{6}$ Therefore, rapid absorption of $\mathrm{CO}_{2}$ can minimize the barotrauma and can rapidly reduce luminal distension. ${ }^{3}$ The superior efficacy of $\mathrm{CO}_{2}$ (vs. room air) in reducing postoperative pain or discomfort during laparoscopic surgery has been established. ${ }^{11}$ However, this has not been extensively evaluated in the field of gastric ESD.

In a recent issue of Clinical Endoscopy, Baniya et al. reported a systematic review and meta-analysis of $\mathrm{CO}_{2}$ vs. room air insufflation in gastric ESD focusing on post-procedural abdominal pain and adverse events. ${ }^{12}$ Unlike a recently published 
meta-analyses ${ }^{11}$ about the efficacy and safety of $\mathrm{CO}_{2}$ (vs. room air) insufflation in ESD (combining gastric, colorectal, and esophageal ESD), this study ${ }^{12}$ focused only on gastric ESD. Therefore, readers can understand the results of this study under the scope of subgroup analysis of the study by Li et al., although this analysis was not conducted in their study. ${ }^{11}$

Although the meta-analyses by Li et al. ${ }^{11}$ and Baniya et al. ${ }^{12}$ commonly claimed less post-procedural abdominal pain or discomfort in the $\mathrm{CO}_{2}$ insufflation group (vs. room air insufflation) of patients with $\mathrm{ESD}^{11}$ or those with gastric $\mathrm{ESD},{ }^{12}$ they could not overcome the methodological limitations. When the enrolled studies report multiple outcomes, it is difficult to select the optimal value for the meta-analysis. Several methods have been proposed to select the representative outcome of studies with multiple outcomes. Averaging the reported values and setting them as a representative value (shifting unit of analysis for subgroup analysis) or selection of one most clinically representative value are typically practiced. ${ }^{13}$

In the meta-analysis by Baniya et al., ${ }^{12}$ the values of three studies (studies by Tanioka et al., ${ }^{14}$ Maeda et al., ${ }^{15}$ and Kim et al. ${ }^{16}$ ) were combined (Table 3 and Fig. 2 in their study ${ }^{12}$ ), while Tanioka et al. ${ }^{14}$ presented only one value (abdominal pain after gastric ESD on a 100-mm visual analogue scale), namely $14.3 \pm 20.5$ ( $\mathrm{CO}_{2}$ group) vs. $24.3 \pm 25.3$ (air group). Maeda et al. ${ }^{15}$ and Kim et al. ${ }^{16}$ presented four values in each study. Therefore, an optimal value should be selected for the meta-analysis in the studies by Maeda et al. ${ }^{15}$ and Kim et al. ${ }^{16}$ Baniya et al. selected maximal post-procedure abdominal pain as the primary effect size to combine. ${ }^{12}$ Therefore, the values $14.3 \pm 20.5\left(\mathrm{CO}_{2}\right.$ group) vs. $24.3 \pm 25.3$ (air group) in the study by Tanioka et al. ${ }^{14}$ and $35.2 \pm 30.3\left(\mathrm{CO}_{2}\right.$ group) vs. $48.5 \pm 29$ (air group) in the study by Kim et al. ${ }^{16}$ were selected for the meta-analysis (Table 3 in their study $\left.{ }^{12}\right)$. However, 1 ( $\mathrm{CO}_{2}$ group) vs. 4 (air group) in the study by Maeda et al. ${ }^{15}$ were selected instead of $4\left(\mathrm{CO}_{2}\right.$ group $)$ vs. 4 (air group), which are the maximal values. ${ }^{12}$ Moreover, the pain level during the first hour after the procedure was the highest in all three studies; however, Baniya et al..$^{12}$ selected only the value observed the next day of the procedure reported in a study by Maeda et al. ${ }^{15}$ Considering the $4\left(\mathrm{CO}_{2}\right.$ group $)$ vs. 4 (air group), which are the maximal values during the first hour after the procedure in the study by Maeda et al., ${ }^{15}$ it is reasonable to choose these values. If these values were used for meta-analysis, the result would be no longer significant.

A recently published meta-analysis by $\mathrm{Li}$ et al. ${ }^{11}$ also claimed less significant post-ESD abdominal discomfort in the $\mathrm{CO}_{2}$ insufflation group (vs. room air insufflation). However, they did not perform subgroup analysis to distinguish between the esophagus, stomach, and colon ESD to evaluate whether they could achieve the expected results. Owing to the differences in database selection and inclusion criteria, there was a discrep- ancy in the enrolled studies on gastric ESD from the study by Baniya et al. ${ }^{12}$ this is another limitation of this method.

Despite its theoretical safety, the superior recovery quality of $\mathrm{CO}_{2}$ insufflation (vs. room air insufflation) is uncertain in various endoscopic procedures, except for colonoscopy. ${ }^{17}$ In addition, the superior recovery quality of $\mathrm{CO}_{2}$ insufflation might not be applicable in gastric ESD, because most of the insufflated agents are excreted by belching or endoscopic suction immediately after a certain amount of air is accumulated in the stomach. Therefore, the influence of insufflated agents might be less significant than that of colonoscopy on abdominal discomfort. Moreover, abdominal discomfort does not depend entirely on the use of insufflated agents, but is also associated with the sedation level of the patient. This was not measurable in this study. ESD-induced iatrogenic ulcer itself can cause abdominal discomfort regardless of the insufflating agents used. The implications of this study are also alleviated, because allocation concealment of enrolled studies, which is the key factor of randomized studies, was not performed or measurable throughout the enrolled studies.

Considering the factors stated above, $\mathrm{CO}_{2}$ insufflation may offer advantages over air insufflation with respect to unexpected serious complications of ESD, especially in gastric perforation. However, it is not an urgent need for relief of abdominal pain or discomfort in gastric ESD, especially for skilled endoscopists.

\section{Conflicts of Interest}

The authors have no financial conflicts of interest.

\section{REFERENCES}

1. Gotoda T. Endoscopic resection of early gastric cancer. Gastric Cancer 2007;10:1-11.

2. Soetikno R, Kaltenbach T, Yeh R, Gotoda T. Endoscopic mucosal resection for early cancers of the upper gastrointestinal tract. J Clin Oncol 2005;23:4490-4498.

3. ASGE Technology Committee, Lo SK, Fujii-Lau LL, et al. The use of carbon dioxide in gastrointestinal endoscopy. Gastrointest Endosc 2016;83:857-865.

4. Yamano HO, Yoshikawa K, Kimura T, et al. Carbon dioxide insufflation for colonoscopy: evaluation of gas volume, abdominal pain, examination time and transcutaneous partial $\mathrm{CO}_{2}$ pressure. J Gastroenterol 2010;45:1235-1240.

5. Bretthauer M, Hoff GS, Thiis-Evensen E, Huppertz-Hauss G, Skovlund E. Air and carbon dioxide volumes insufflated during colonoscopy. Gastrointest Endosc 2003;58:203-206.

6. Saltzman HA, Sieker HO. Intestinal response to changing gaseous environments: normobaric and hyperbaric observations. Ann N Y Acad Sci 1968;150:31-39.

7. Kawahara Y, Okada H, Yamamoto K. Prevention and management of ESD complications: Two cases of air embolism during ESD procedures. Gastroenterological Endoscopy 2009;51(Suppl 2):2086.

8. Green BT, Tendler DA. Cerebral air embolism during upper endoscopy: case report and review. Gastrointest Endosc 2005;61:620-623. 
9. Takeuchi $\mathrm{H}$, Abe N, Sugiyama M. A case of air embolism during gastric ESD. Gastroenterological Endoscopy 2012;54(Suppl 1):893.

10. Becker GL. The prevention or gas explosions in the large bowel during electrosurgery. Surg Gynecol Obstet 1953;97:463-467.

11. Li X, Dong $\mathrm{H}$, Zhang Y, Zhang G. $\mathrm{CO}_{2}$ insufflation versus air insufflation for endoscopic submucosal dissection: a meta-analysis of randomized controlled trials. PLoS One 2017;12:e0177909.

12. Baniya R, Upadhaya S, Khan J, et al. Carbon dioxide versus air insufflation in gastric endoscopic submucosal dissection: a systematic review and meta-analysis of randomized controlled trials. Clin Endosc 2017;50:464-472.

13. Cooper H. Synthesizing research : a guide for literature reviews. 3rd ed. Thousand Oaks (CA): SAGE; 1998.

14. Tanioka D, Kawahara Y, Okada H, et al. Safety and efficacy of carbon dioxide $\left(\mathrm{CO}_{2}\right)$ insufflation during endoscopic submucosal dissection (ESD) for gastric cancer under propofol sedation: a randomized, controlled trial. Gastrointest Endosc 2008;67:AB279.

15. Maeda Y, Hirasawa D, Fujita N, et al. A prospective, randomized, double-blind, controlled trial on the efficacy of carbon dioxide insufflation in gastric endoscopic submucosal dissection. Endoscopy 2013;45:335341.

16. Kim SY, Chung JW, Park DK, Kwon KA, Kim KO, Kim YJ. Efficacy of carbon dioxide insufflation during gastric endoscopic submucosal dissection: a randomized, double-blind, controlled, prospective study. Gastrointest Endosc 2015;82:1018-1024.

17. Wang WL, Wu ZH, Sun Q, et al. Meta-analysis: the use of carbon dioxide insufflation vs. room air insufflation for gastrointestinal endoscopy. Aliment Pharmacol Ther 2012;35:1145-1154. 